\title{
Diagnostic Value of Electrocardiographic ST-T Wave Changes in Lead aVL in Patients with Chronic Stable Angina
}

\author{
Mohamad Osama Kayed, Aly Aly Ramzy, Ibrahim Yassin, \\ Eslam Ismail Zakria Kotb \\ Department of Cardiology, Faculty of Medicine, Alazhar University \\ Corresponding Author: Eslam Ismail Zakria Kotb,Phone: 01003334493,email:Dreslamkotb222@ gmail.com
}

\begin{abstract}
Background: coronary artery diseases affect millions of patients in the world which cause a lot of complications up to death. by very simple non-invasive method like ECG we can predict and early diagnose and even localize very serious lesion in coronary angiograghy in patient with chronic stable angina and this is the target of our research. Aim of Work: this study aimed to detect the diagnostic value of ST segment and T wave changes in lead AVL in patient with chronic stable angina. Methods: this was a prospective observation study that was done from June 2017 to July 2018 and it included 200 patients presented to Alhussin University Hospital or referred to us from other secondary hospitals with chronic stable angina. All patients were subjected to full history, clinical examination, ECG and coronary angiograms with focusing on ST segment and T wave changes and analyses and localized the lesions in coronary angiograms and their relationship to previous ECG changes. Results: mean age in patients in our study was 55.89 years old with $77 \%$ males and $23 \%$ females. Most common risk factor was HTN. There was a relationship between ST-T wave changes in lead AVL in patient with chronic stable angina with moderate agreement to mid LAD lesion $78 \%$ and to lesser degree LCX then RCA and LM. Conclusion: according to the previous results of our research, inverted T wave in lead AVL in chronic stable angina corresponds angiographically to tight mid left anterior descending coronary artery lesion.
\end{abstract}

Keywords: ECG,aVI,t wave,St segment chronic stable angina.

\section{Introduction}

Coronary heart disease also called coronary artery diseases affect millions of people around the world which cause a lot of complications up to death ${ }^{(1)}$. About 71 million in USA are suffering from cardiovascular complications that represented 1 in every 2.5 adult including 15 million with coronary artery disease and about 10 million are suffering from angina. In the age group of 60 to 79 years old about $25 \%$ of men and $17 \%$ of women had a very serious IHD and these numbers rise to 35 $\%$ for men and $24 \%$ for women in the age group above 80 years old ${ }^{(2)}$. In additional to data obtained from the World Health Organization (WHO) there was a national project (the Egyptian National Hypertension Project) that provided us by important information on the epidemiology of the coronary heart disease in Egypt. The data base that obtained from this project which represented survey of 6733 subjects $50 \%$ male and $50 \%$ was females; 8.5 of this survey were suffering from coronary heart disease. It was noticed that females were more affected $8.9 \%$ and males $8.3 \%$, but it was clearly associated with an urban versus rural location (8.8\% versus $7 \%$ ) and age group $\geq 50$ years vs $<50$ years $(11 \% \text { vs } 5 \%)^{(3-5)}$. As we know there are three main coronary arteries that supply the myocardium (LAD>>left anterior descending artery) and (RCA >> right coronary artery) and (LCX > left circumflex artery).LAD supplies $60 \%$ to $70 \%$ of the left ventricular myocardium and early management of its proximal obstruction is mandatory to prevent major myocardium ischemic damage ${ }^{(6)}$. So, early diagnosis and treatment of LAD obstructive lesion is very important to prevent serious damage of the main pump power of the heart (the left ventricle).ECG is an important fast, non invasive, safe, bedside and cheap method to diagnosis acute or chronic heart disease which provides important diagnostic and prognostic information about the patient with chest pain. Inverted $\mathrm{T}$ wave and ST segment depression are a very important sign of ischemia in patient with chest pain and is always associated with $\mathrm{CAD}{ }^{(7)}$. Localization of coronary heart disease narrowing or obstructive lesion and localization of the anatomic site of myocardiaL infarction are dependent on the localization of T wave or ST segment changes 
and abnormal pathalogical Q wave in 12 leads $\mathrm{ECG}^{(8,9)}$.

This study was dependent on autopsy series correlation the site of mycardial infarction or coronary artery narrowing's with the location of previous ECG changes on antemortem ECG.

\section{Patients}

The research on 200 patients presented to Alhussin University Hospital or referred from secondary hospitals which are already diagnosed as coronary heart disease by non invasive methods ECG, echocardiography, treadmill stress exercise, myocardial perfusion imaging and multi slice CT coronary and referred to us to do the invasive coronary angiograghy.

\section{Methods}

The study was done on 200 patients presented for admission in Alhussin University Hospital or referred from secondary hospitals where they already diagnosed as Coronary heart disease by non invasive methods like ECG, Treadmill stress Ecg and $\mathrm{Ct}$ coronary angiograghy.

Each patient was subjected to:

1. Full history taking

2. Full clinical examination

3. ECG

We prepared patient carefully by 12 leads ECGs were recorded in the format at paper speed $25 \mathrm{~mm}$ per one second and calibrated correctly.Cardiology resident or specialist interpreted the data obtained from the ECG with special focus to $T$ wave and ST segment changes and pathalogical Q waves and specially in aVl lead in chronic stable angina.Changes in $\mathrm{T}$ waves in lead aVl were divided into upright,inverted and flat $\mathrm{T}$ wave. Changes in ST segment changes were divided into raised, depressed and isoelecrical ST segment. Coronay anghiograms were done and analyzed by interventional cardiologist.

Lesions of main branches of coranary system (LM, LAD, RCA,LCX ) were divided according to the site of the lesion into the ostial lesion which was defined as leasion affected the origin of the vessel or within $3 \mathrm{~mm}$ from the origin.

Left anterior descending artery was divided anatomicaly into:

1. Proximal LAD $3 \mathrm{~mm}$ from $\mathrm{LAD}$ origin into first diagonal brache D1 A

Mid LAD lesion from DI to D2

Distal LAD lesion beyond D2

2. Left circumflex artery was divided anatomically into

Proximal LCX leasion $3 \mathrm{~mm}$ from LCX origin to first obtuse marginal OM1 branch.

Mid LCX leasion from OM1 to OM2

Distal LCX lesion beyond the OM2 branch

3. Proximal right coronary artery (RCA) $3 \mathrm{~mm}$ from the origin into $\mathrm{rt}$ ventricular branch

Mid RCA lesion is from the right ventricular branch to RCA bifurcation

Distal RCA lesion is beyond the bifurcation of the RCA

The study was approved by the Ethics Board of Al-Azhar University.

\section{Results}

\section{Basic Characteristic Data}

Male was more affected in this study than female.

Table 1: gender (n 200)

\begin{tabular}{||c|c|c||}
\hline & No. & \% \\
\hline Gender & & \\
Male & 154 & 77.0 \\
Female & 46 & 23.0 \\
\hline
\end{tabular}

$36 \%$ of the patients were aged below 50 years and $(64 \%)$ were above 50 years age. The mean age was $56.89 \pm 10.33$ years. 


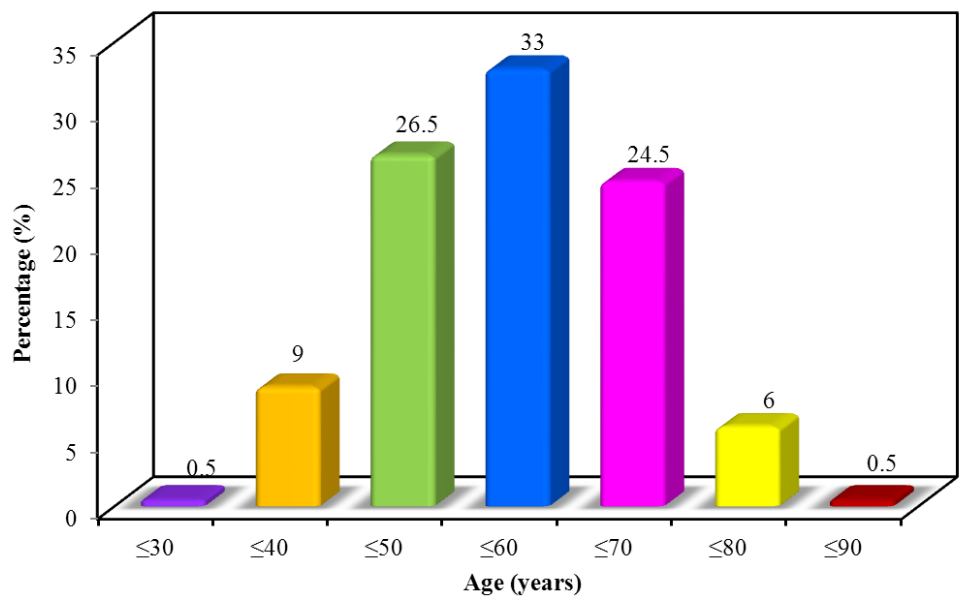

Figure 1: age

Smoking and hypertension were the most prevalent risk factors, 129 patients $(64.5 \%)$ were smokers, 120 patients $(60.3 \%)$ were hypertensive on medications then DM and DLP, and combination of both smoking and hypertension were found in 68 patients (33.3\%).

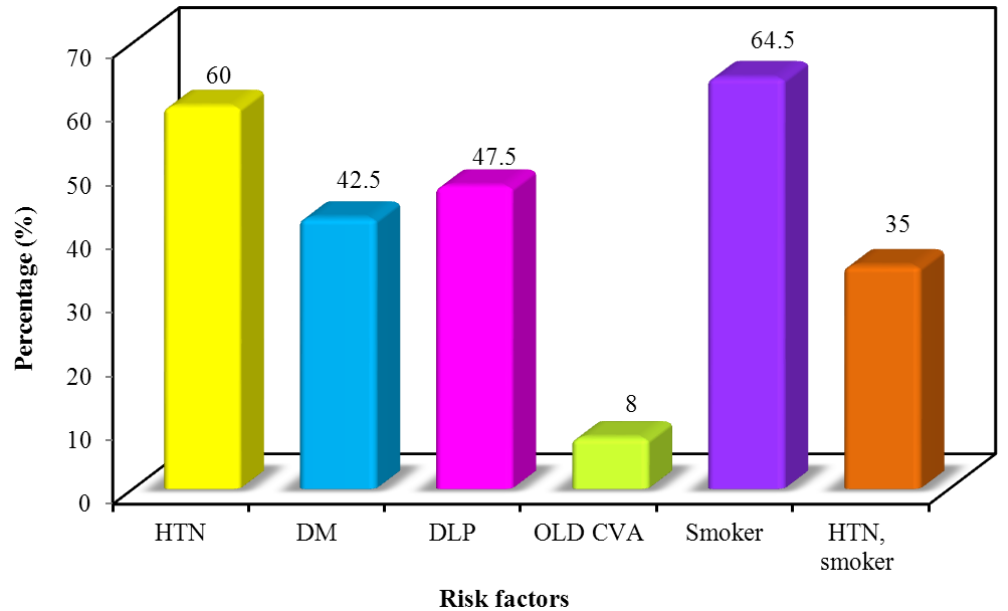

Figure 2: distribution of the studied cases according to risk factors $(\mathbf{n}=200)$

\section{Angioghraphic data}

Left anterior descending artery (LAD) was the most commonly affected coronary artery 139 (69.5\%), far beyond followed by right coronary artery (RCA) 82 (41.0\%), posterolateral artery 54 (27 $\%)$, left circumflex artery (LCX) 69 (34.6\%), respectively.

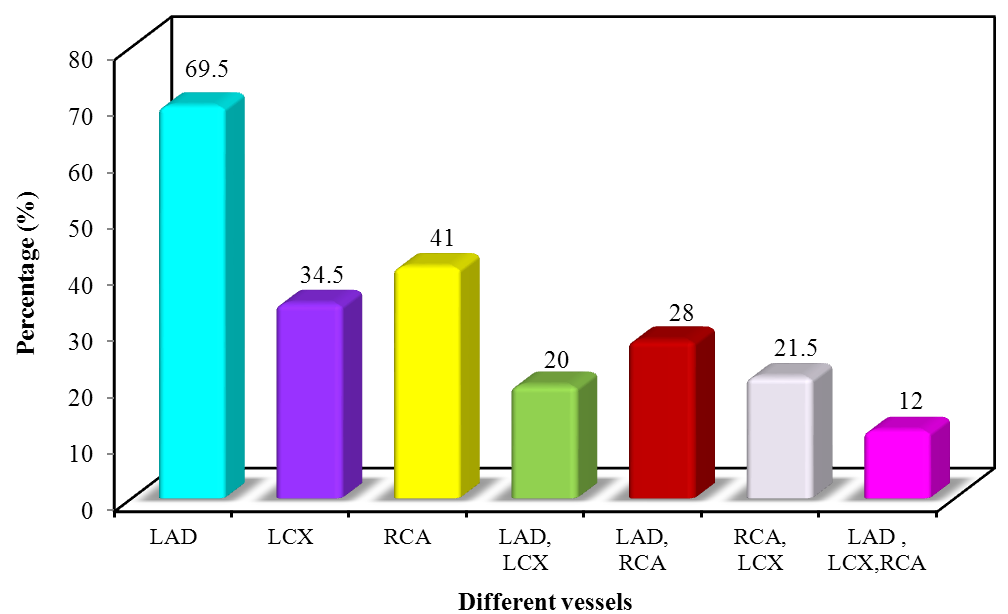

Figure 3: distribution of the studied cases according to different vessels $(n=200)$ 


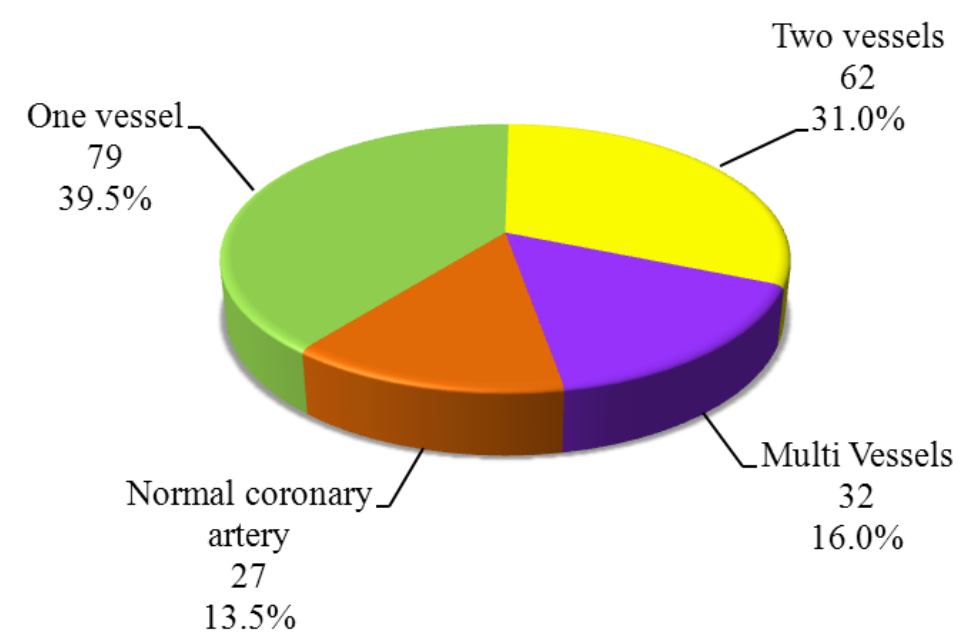

Figure 4: distribution of the studied cases according to different vessels $(n=200)$

\section{Segmental Coronary Artery Stenosis}

Lesions mid LAD lesions were the most prevalent than other LAD lesions accounting for 97 lesions (48.5\%). Proximal LCX lesions (41 lesions, 20.5\%) were the most common in all LCX lesions. Also the mid RCA lesions (44 lesions, 22\%) were the common in all RCA lesions.

Table 6: distribution of the studied cases according to angio $(\mathbf{n}=\mathbf{2 0 0})$

\begin{tabular}{|c|c|c|c|c|c|c|}
\hline \multirow[t]{2}{*}{ Angio } & \multicolumn{2}{|c|}{$\begin{array}{c}\text { LAD } \\
(\mathbf{n}=\mathbf{1 3 9})\end{array}$} & \multicolumn{2}{|c|}{$\begin{array}{c}\text { LCX } \\
(n=69)\end{array}$} & \multicolumn{2}{|c|}{$\begin{array}{c}\text { RCA } \\
(n=82)\end{array}$} \\
\hline & No. & $\%$ & No. & $\%$ & No. & $\%$ \\
\hline Ostial & 1 & 0.5 & 26 & 13.0 & 14 & 7.0 \\
\hline Proximal & 46 & 23.0 & 41 & 20.5 & 27 & 13.5 \\
\hline Mid & 97 & 48.5 & 7 & 3.5 & 44 & 22.0 \\
\hline Distal & 22 & 11.0 & 14 & 7.0 & 25 & 12.5 \\
\hline
\end{tabular}

\section{Electrocardiogram}

Most of patients were sinus rhythm with normal axis and inverted T wave and isoelectrical ST segment and mean heart rate was 75 .

Table 7: distribution of the studied cases according to ECG $(\mathbf{n}=\mathbf{2 0 0})$

\begin{tabular}{|c|c|c|}
\hline ECG & No. & $\%$ \\
\hline SR & 188 & 94.0 \\
\hline A.FIB & 13 & 78.5 \\
\hline N.AXIS & 157 & 78.5 \\
\hline LAD & 29 & 14.5 \\
\hline RAD & 13 & 6.5 \\
\hline Upright T Avl & 75 & 37.5 \\
\hline Flat T Avl & 34 & 17.0 \\
\hline Inverted T Avl & 91 & 45.5 \\
\hline ST ISO & 167 & 83.5 \\
\hline ST DEP & 23 & 11.5 \\
\hline ST ELEV & 10 & 5.0 \\
\hline CAD Other leads & 82 & 41.0 \\
\hline T Inversion Without Evidence & 55 & 27.5 \\
\hline Evidence Cad With Normal aVL & 34 & 17.0 \\
\hline $\begin{array}{l}\text { Others (Frequent PVCs, poor R progression, } T \\
\text { wave alternass, ....,etc) }\end{array}$ & 14 & 7.0 \\
\hline $\begin{array}{l}\text { HR } \\
\quad \text { Min. }- \text { Max. } \\
\quad \text { Mean } \pm \text { SD }\end{array}$ & \multicolumn{2}{|c|}{$\begin{array}{c}54.0-125.0 \\
75.08 \pm 13.89\end{array}$} \\
\hline
\end{tabular}




\begin{tabular}{|c|c|c|c|c|c|c|c|c|c|}
\hline & \multicolumn{4}{|c|}{$\begin{array}{c}\text { Inverted T with } \\
\text { in lead Avl }\end{array}$} & \multirow{3}{*}{$\square^{\square}$} & \multirow{3}{*}{$\mathbf{p}$} & \multirow{3}{*}{$\begin{array}{c}\text { Accordance } \\
\text { (Accuracy) }\end{array}$} & \multirow{3}{*}{$\mathbf{K}$} & \multirow{3}{*}{ Agreement } \\
\hline & \multicolumn{2}{|c|}{$\begin{array}{c}\text { No } \\
(\mathrm{n}=109)\end{array}$} & \multicolumn{2}{|c|}{$\begin{array}{c}\text { Yes } \\
(n=91)\end{array}$} & & & & & \\
\hline & No. & $\%$ & No. & $\%$ & & & & & \\
\hline $\mathbf{L M}$ & 7 & 6.4 & 3 & 3.3 & 1.020 & ${ }^{\mathrm{FE}} \mathrm{p}=0352$ & $52.50 \%$ & -0.034 & Poor agreement \\
\hline Mid LAD & 26 & 23.9 & 71 & 78.0 & $58.262^{*}$ & $<0.001^{*}$ & $77.0 \%$ & $0.539^{*}$ & Moderate agreement \\
\hline Ostial LAD & 1 & 0.9 & 0 & 0.0 & 0.839 & ${ }^{F E} \mathrm{p}=1.000$ & $54.0 \%$ & -0.010 & Poor agreement \\
\hline Proximal LAD & 32 & 29.4 & 14 & 15.4 & 5.468 & $0.019^{*}$ & $45.50 \%$ & $-0.146^{*}$ & Poor agreement \\
\hline Destal LAD & 22 & 20.2 & 0 & 0.0 & $20.637^{*}$ & $<0.001^{*}$ & $43.5 \%$ & $-0.215^{*}$ & Poor agreement \\
\hline Ostial LCX & 25 & 22.9 & 1 & 1.1 & $20.910^{*}$ & $<0.001^{*}$ & $42.50 \%$ & $-0.232^{*}$ & Poor agreement \\
\hline Proximal LCX & 37 & 33.9 & 4 & 4.4 & $26.571^{*}$ & $<0.001^{*}$ & $38.0 \%$ & $-0.310^{*}$ & Poor agreement \\
\hline Mid LCX & 2 & 1.8 & 5 & 5.5 & 1.967 & ${ }^{F E} \mathrm{p}=0.249$ & $56.0 \%$ & 0.040 & Poor agreement \\
\hline Destal LCX & 7 & 6.4 & 7 & 7.7 & 0.123 & 0.726 & $54.5 \%$ & 0.014 & Poor agreement \\
\hline Ostial RCA & 1 & 0.9 & 13 & 14.3 & $13.615^{*}$ & $<0.001^{*}$ & $60.5 \%$ & $0.144^{*}$ & Poor agreement \\
\hline Proximal RCA & 23 & 21.1 & 4 & 4.4 & $11.852^{*}$ & $0.001^{*}$ & $45.0 \%$ & $-0.177^{*}$ & Poor agreement \\
\hline Mid RCA & 37 & 33.9 & 7 & 7.7 & $19.919^{*}$ & $<0.001^{*}$ & $38.5 \%$ & $-0.274^{*}$ & Poor agreement \\
\hline Distal RCA & 19 & 17.4 & 6 & 6.6 & $5.326^{*}$ & $0.021^{*}$ & $48.0 \%$ & -0.115 & Poor agreement \\
\hline
\end{tabular}

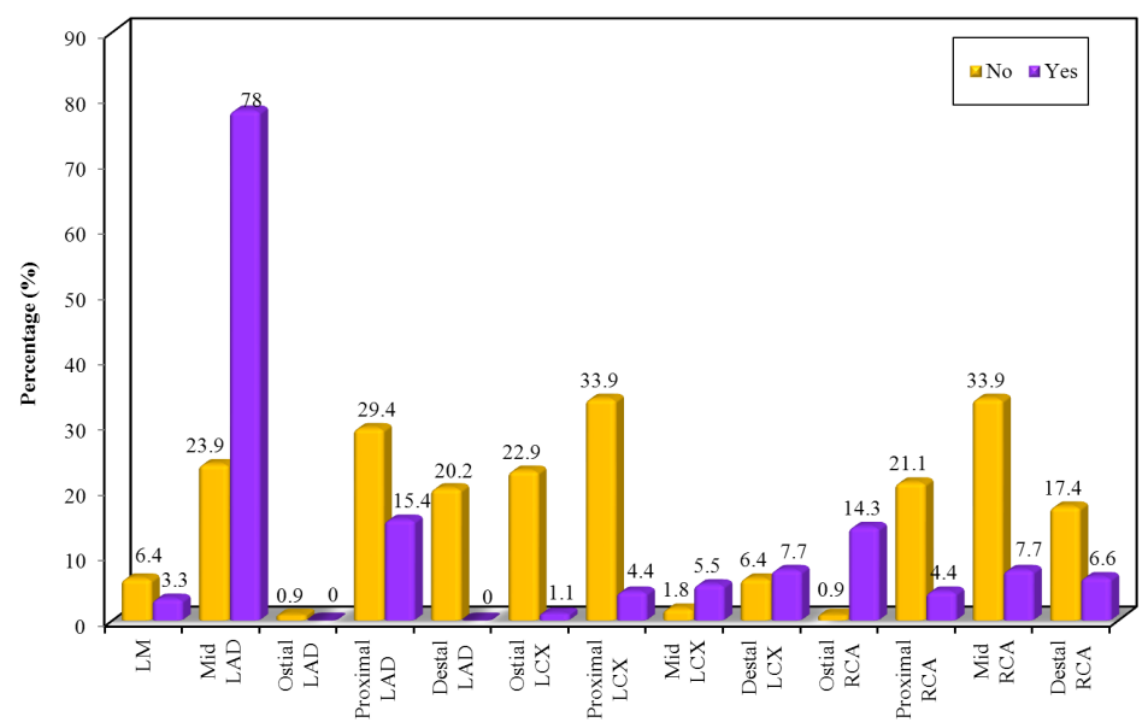

Figure 5: relation between Inverted $T$ within lead aVL and different coronary artery segments lesions

\section{Discussion}

The electrocardiogram (ECG) is a simple and non-invasive bedside diagnostic tool with a well-established role in the diagnosis of CAD. Many studies have found that the admission ECG provides important prognostic information in patients admitted with chest pain. For instance, $\mathrm{T}$ wave inversion in anterior or inferior location and or ST-segment depression has been associated with high incidence of $\mathrm{CAD}^{(10,11)}$. Fuchs et al. studied the electrocardiographic localization of coronary artery narrowing during myocardial ischemia and infarction in patients with one-vessel disease $^{(12)}$. This study prospectively included 200 patients diagnosed as chronic stable angina, collected from Al-hussin University Hospital, cardiology Department. In the present study, the mean age at presentation was $55.89 \pm 10.33$ years, $77 \%$ were males, $42.5 \%$ had diabetes, 60 $\%$ were hypertensive, $64.5 \%$ were smokers, $47.5 \%$ were dyslipidemic and $8 \%$ had history of old cerebrovascular stroke. Hypertension and 
smoking were the most common risk factors found in $35 \%$ of the study population. We meant by smoking in our study either cigarettes or shisha smoking. Farhan et al. ${ }^{(13)}$ studied the diagnostic value of electrocardiographic $\mathrm{T}$ wave inversion in lead aVL in diagnosing coronary artery disease in patients with chronic stable angina. This study reported that from December 2008 to April 2009 at sultan Qabos university hospital, a total of 191 patients undergoing coronary angiography were analyzed. All patients had chronic stable angina. The mean age was $55.2 \pm 11.5$ years, $71.2 \%$ were males, $37.2 \%$ had diabetes, $44 \%$ were hypertensive, $21 \%$ were dyslipidemic, $25.7 \%$ had history of old myocardial infarction and $4.7 \%$ had history of old cerebrovascular stroke. There were no data about smoking as a well established risk factor of coronary artery disease worldwide ${ }^{(13)}$.In the current study, we found that sinus rhythm is the predominant rhythm accounting for $94 \%$ of patients while the rest of the patients $(6 \%)$ were in atrial fibrillation rhythm and inverted $\mathrm{T}$ wave in lead aVL was reported in 91 patients $(45.5 \%)$ while 75 patients $(37.5 \%)$ had upright $\mathrm{T}$ wave in lead aVL and 34 patients $(17 \%)$ had flat $\mathrm{T}$ wave in lead aVL. In the current study, ST segment in lead aVL was isoelectric in 167 patients (83.5), depressed in 23patients (11.5\%) and elevated in 10 patients $(5 \%)$.We also found that $\mathrm{T}$ wave inversion in lead aVL without evidence of ischemia in other leads was found in 55 patients $(27.5 \%)$ while evidence of ischemia in other leads with normal aVL was found in 34 patients (17\%).Farhan et al. found that the prevalence of $\mathrm{T}$ wave inversion in lead aVL, was $46.8 \%$ while flat and upright $\mathrm{T}$ wave were seen in $12.8 \%$ and $40.4 \%$ respectively. Stand alone $\mathrm{T}$ wave inversion in lead aVL was found in 27 ECGs $(14.1 \%)$ with no pathological Qs and or ST-T changes ${ }^{(13)}$. We found in the current study that left anterior descending artery lesion was the most common coronary artery lesions (139 lesion, 69.5\%), far beyond followed by right coronary artery lesions ( 82 lesions, 41\%), posterior lateral artery lesions (54 lesions, 27\%) left circumflex artery lesions (69 lesions, 34.5\%) and ramus artery lesions (32 lesions, 16\%).Farhan et al. found that the left anterior descending artery was 117 lesions $(61.2 \%)$, the most common coronary artery affected, followed by the right coronary artery (85 lesions, 44.5\%) and the diagonal arteries

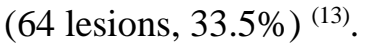

\section{Conclusion}

According to the previous results of our research, inverted $\mathrm{T}$ wave in lead $\mathrm{aVL}$ in chronic stable angina corresponds anghioghraphically to tight mid left anterior descending coronary artery lesion.Such important ECG data that can be obtained easily from preoperative assessment before noncardiac surgery can suspect significant coronary heart disease especially to GP Doctors.

\section{Recommendations}

This research recommended that changes in ST segment or T wave changes in lead aVL in chronic stable angina is very important for management and prediction of the outcome of the patient condition so focus on this changes while reading our ECG. We need to do more studies to study the site of coronary artery leasions and relation to different ECG criteria by which we can predict very serious coronary artery condition by very simple non invasive method ECG.

\section{References}

1. Mensah GA and Bpsprown DW(2007): An overview of cardiovascular disease burden in the United States. Health Affairs, 26:38-48.

2. Lloyd-Jones D, Adams RJ, Brown TM, Carnethon M, Dai S, De Simone G et al. (2010) Executive summary: heart disease and stroke statistics--2010 update: a report from the American Heart Association. Circulation, 121:948-953

3. Almahmeed W, Arnaout MS, Chettaoui R, Ibrahim M, Kurdi MI, Taher MA et al.(2012) Coronary artery disease in Africa and the Middle East. Ther. Clin. Risk Manag., 8:65-72.

4. Ibrahim MM, Rizk H, Appel LJ, El Aroussy W, Helmy S, Sharaf Y et al .(1995) Hypertension prevalence, awareness, treatment and control in Egypt results from the Egyptian National Hypertension Project (NHP). Hypertension, 26:886-90.

5. Ibrahim MM, Appel LJ, Rizk HH, Helmy S, Mosley J, Ashour Z et al. (2001): Cardiovascular risk factors in normotensive and hypertensive Egyptians. J. Hypertension, 19:19331940. 
6. Mill MR, Wilcox BR, Anderson RH et $a l$. (2003) Surgical anatomy of the heart. In: Cardiac Surgery in the Adult .Cohn LH, Edmunds LH Jr (eds). New York: McGrawHill; pp: 31-52.

7. Surawicz B and Knilans TK (2001) Chou's Electrocardiography in Clinical Practice. $5^{\text {th }}$ ed. W.B. Saunders Co Philadelphia.

8. Chung EK (1980): ElectrocardiographyPractical Applications with Vectorial Principles: Harper Collins Publishers. London.

9. Surawicz B and Knilans TK (2008) Chou's electrocardiography in Clinical Practice: Adult and Pediatric. ${ }^{\text {th }}$ ed.: WB Saunders Co; Philadelphia .

10. Tamura A, Kataoka H, Mikuriya $Y$, Nasu M et al .( 1995) Inferior ST segment depression as a useful marker for identifying proximal left anterior descending artery occlusion during acute anterior myocardial infarction. Eur. Heart J.,16:1795-1800.
11. Engelen DJ, Gorgels AP, Cheriex EC, De Muinck ED, Ophuis AJ, Dassen WR et al .(1999) Value of the electrocardiogram in localizing the occlusion site in the left anterior descending coronary artery in acute anterior myocardial infarction. J. Am. Coll. Cardiol., 34:389-395.

12. Fuchs RM, Achuff S, Grunwald L, Yin F, Griffith $\mathrm{L}$ et al. (2011) Electrocardiographic localization of coronary artery narrowing: studies during myocardial ischemia and infarction in patients with one-vessel disease. Circulation, 66:1168-1176.

13. Farhan HL, Hassan KS, Al-Belushi A, Sallam M, Al-Zakwani I et al. (2010) Diagnostic value of electrocardiographic $\mathrm{T}$ wave inversion in lead aVL in diagnosing coronary artery disease in patients with chronic stable angina. Oman Med. J., 25:124-131. 